\title{
Enzymatic activity of type 1 iodothyronine deiodinase in selected liver tumors
}

Oskar Kornasiewicz ${ }^{1}$, Marcin Dębski², Michal Grat ${ }^{1}$, Barbara Lenartowicz', Marta Stępnowska², Anna Szałas², Ewa Bar-Andziak², Marek Krawczyk ${ }^{1}$

${ }^{1}$ Department of General, Transplant and Liver Surgery, Medical University of Warsaw, Poland

2Department of Internal Medicine and Endocrinology, Medical University of Warsaw, Poland

Submitted: 25 August 2012

Accepted: 28 February 2013

Arch Med Sci 2014; 10: 4: 801-805

DOI: 10.5114 /aoms.2013.34323

Copyright (C) 2014 Termedia \& Banach

\section{Abstract}

Introduction: Type 1 iodothyronine deiodinase (D1) converts thyroxin (T4) into triiodothyronine (T3). Strong evidence indicates that thyroid hormone metabolism is disturbed in neoplasms such as thyroid and breast cancer. However, there is limited data concerning the function of the D1 enzyme in liver tumors. We aimed to estimate the enzymatic activity of D1 in two different common liver tumors. Material and methods: We obtained 20 tumor samples from patients who had undergone a liver resection. Of the tissue samples, there were 13 benign lesions of focal nodular hyperplasia (FNH) and 7 malignant lesions of hepatocellular carcinomas (HCC). The D1 activity was assessed by measuring the amount of radioactive iodine released in reaction to D1-catalysed deiodination. Groups were compared by the Mann-Whitney non-parametrical test for independent trials, and the Kruskal Wallis test.

Results: The enzymatic activity of D1 was not significantly altered in the FNH group $($ median $=536 \mathrm{fmol} / \mathrm{mg}$ of protein $/ \mathrm{min} ; p=0.972)$ and HCC group (367 $\mathrm{fmol} / \mathrm{mg} ; p=0.128$ ) when compared to matched normal liver parenchyma controls (546 fmol/mg and $556 \mathrm{fmol} / \mathrm{mg}$, respectively).

Conclusions: Liver parenchyma expresses high levels of D1. The results clearly revealed that D1 activity was not significantly different between benign and malignant tumors (FNH and $\mathrm{HCC}$ ) compared to healthy liver parenchyma cells.

Key words: thyroxin, hepatocellular carcinomas, focal nodular hyperplasia.

\section{Introduction}

Thyroid hormones play an important role in cell development, growth, division, and apoptosis. They act through their nuclear receptors and affect the transcription and translation processes. Thyroxine (T4), which is the main product of the thyroid gland, is a pro-hormone that is converted into triiodothyronine (T3) following activation by monodeiodination. The reaction is catalyzed by deiodinase type 1 (D1) and type 2 (D2). Deiodinase type 1 is mainly present in liver, kidneys, and thyroid [1]. The role of D2 had been underestimated until a recent study detected its presence in skeletal muscle [2].

For many years, it has been postulated that since thyroid hormones influence cell growth and differentiation, they may play an important role

\author{
Corresponding author: \\ Oskar Kornasiewicz MD, PhD \\ Department of General, \\ Transplant and Liver Surgery \\ Medical University of Warsaw \\ 1 A Banacha St \\ 02-097 Warsaw, Poland \\ Phone: + 48600229933 \\ E-mail: \\ oskar.kornasiewicz@gmail.com
}


in carcinogenesis. However, available data have been insufficient to achieve complete understanding of this process [1]. The enzymatic activity and gene expression of D1 have been investigated in different cancer tissues. A significant decrease in both the gene expression and enzyme activity of D1 was detected in papillary thyroid cancer tissue $[3,4]$ as well as in papillary and follicular thyroid cancer cell lines [5, 6]. Reduced D1 enzymatic activity and/or mRNA expression has also been described in liver hemangioma [7], renal clear cell cancer [8], lung cancer [9] and pituitary adenomas $[10,11]$. Interestingly, elevated D1 enzymatic activity and mRNA expression have been reported in human breast cancer tissue $[12,13]$. There is evidence demonstrating that thyroid hormone metabolism is altered in neoplastic tissues [14, 15]. Some studies have reported deiodinase activity in liver lesions. High levels of deiodinase type 3 , which inactivates thyroid hormones, have been discovered in liver hemangiomas [16-18].

The aim of the present study was to investigate the enzymatic activity of D1 in selected liver tumors - focal nodular hyperplasia (FNH) and hepatocellular carcinoma (HCC) - and compare it to the corresponding levels in healthy liver parenchyma.

Focal nodular hyperplasia is a benign hepatic tumor unlike HCC, which is a malignant hepatic tumor with poor outcome. Hepatocellular carcino$\mathrm{ma}$ is the most common primary liver cancer secondary to liver cirrhosis and is more common in men, whereas FNH occurs more frequently in women and is the second most prevalent benign tumor of the liver, requiring surgical intervention only in rare cases [19-21].

\section{Material and methods}

We obtained 20 tumor samples and liver tissue from patients who underwent liver resections. All the patients were clinically euthyroid prior to the operation. There were 13 cases with FNH and 7 with HCC (Table I). The samples were obtained from the tumor as well as from a site distant from the tumor location, which were macroscopically found to be normal liver parenchyma. These non-cancerous tissues were used as the controls. Immediately after the operation, the collected samples were frozen in dry ice and stored at $-70^{\circ} \mathrm{C}$ until analysis.

Tissue samples were thawed and homogenized in homogenization buffer (0.1 M PE $\left[\mathrm{K}_{2} \mathrm{HPO}_{4} / \mathrm{KH}_{2} \mathrm{PO}_{4}\right]$,
$1 \mathrm{~mm}$ ethylene diamine tetraacetic acid (EDTA), $10 \mathrm{mM}$ dithiothreitol (DTT) and $0.25 \mathrm{M}$ sucrose, $\mathrm{dH}_{2} \mathrm{O}$, $\mathrm{pH}$ 7.0). The protein concentration was estimated by the bicinchoninic acid (BCA) method using bovine serum albumin as the protein standard.

Deiodinase type 1 activity was measured by quantifying the radioactive iodide released from 3/5/[125I]-rT3, which was purified just prior to each assay by chromatography in a Sephadex $\mathrm{LH}-2 \mathrm{O}$ column $[8,22]$. It was washed out with $10 \mathrm{ml}$ of $\mathrm{H}_{2} \mathrm{O}$ followed by elution with $2 \mathrm{ml}$ of $75 \%$ ethanol in 0.5- $\mathrm{ml}$ fractions (this amount of alcohol did not affect the reaction). Fractions with the highest activity were selected (50 000-60000 CMP), and $70 \mu \mathrm{l}$ was added into each reaction tube.

The samples were incubated in phosphate buffer (0.1 M PE and $1 \mathrm{mM}$ EDTA; $\mathrm{pH}=6.9$ ) for $30 \mathrm{~min}$ at $37^{\circ} \mathrm{C}$ along with $1 \mathrm{nM}$ unlabeled $\mathrm{rT3}$ and $10 \mathrm{mM}$ DTT. Each assay was performed twice and there was always one extra sample containing propylthiouracil (PTU) to show D1 inhibition by this agent. After incubation, the reaction was stopped by placing the samples in an ice bath. The samples were then precipitated by addition of $100 \mu \mathrm{l}$ of horse serum and $50 \mu \mathrm{l}$ of $50 \%$ trichloroacetic acid (TCA). The samples were then vortexed for $1.5 \mathrm{~min}$ and centrifuged at $9000 \mathrm{rpm}$ for $5 \mathrm{~min}$. An aliquot of the supernatant containing [125|] but not labeled iodothyronine was counted in a gamma counter (Wizard1470, Wallac). The final enzymatic activity was expressed as fmol of released [125I] per mg protein per minute.

\section{Statistical analysis}

Statistical analysis was performed with the use of the "STATISTICA" software (StatSoft, Inc. Oklahoma, USA). All data was reported as median and range values. Groups were compared by the MannWhitney non-parametrical test for independent trials and the Kruskal Wallis test.

\section{Results}

The enzymatic activity was not significantly altered in the $\mathrm{FNH}$ group $(536 \mathrm{fmol} / \mathrm{mg}$ of protein/min; range: 321-1149) as compared to the healthy controls $(546 \mathrm{fmol} / \mathrm{mg}$ of protein $/ \mathrm{min}$; range: $56-1211)(p=0.972)$ (Figures 1 and 2). Further, the enzymatic activity in the HCC group (367 $\mathrm{fmol} / \mathrm{mg}$ of protein/min; range: 9-553) was not significantly altered as compared to the healthy liv-

Table I. Demographic data

\begin{tabular}{|lcccc|}
\hline Diagnosis & Number of cases & \multicolumn{2}{c|}{ Age [years] } \\
\cline { 3 - 5 } & & Minimum & Average & Maximum \\
\hline FNH & 13 & 18 & 28 & 41 \\
\hline HCC & 7 & 31 & 55 & 73 \\
\hline
\end{tabular}




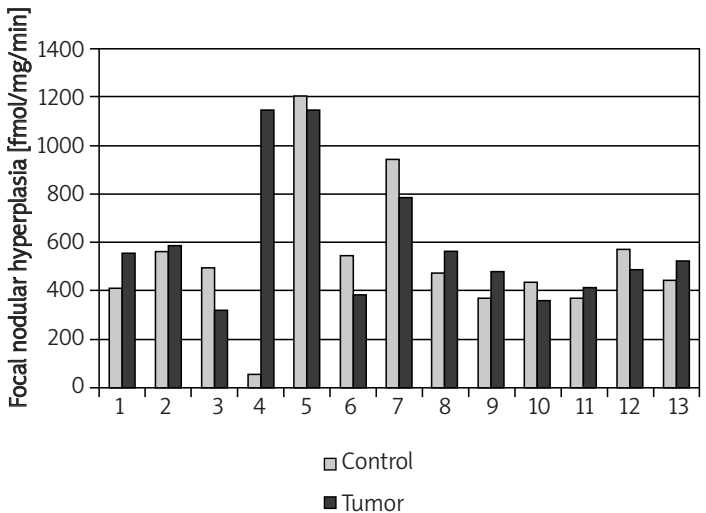

Figure 1. D1 activity in each of the 13 cases of focal nodular hyperplasia (FNH)

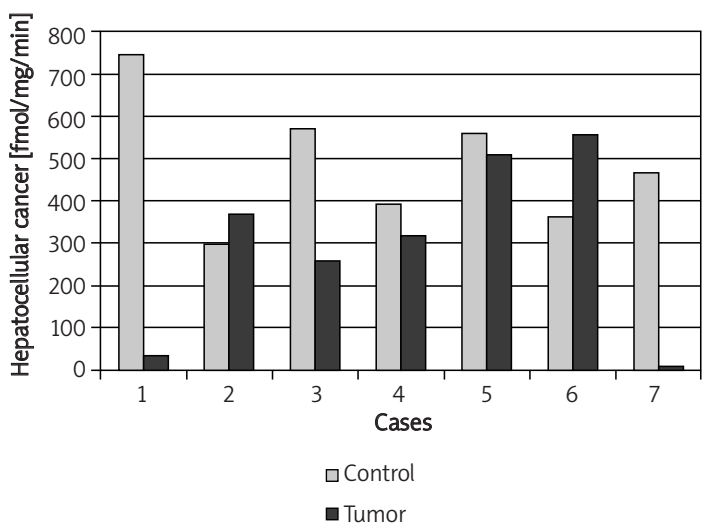

Figure 3. D1 activity in each of the 7 cases of hepatocellular cancer (HCC)

er controls (556 fmol/mg of protein/min; range: 297-744) $(p=0.128)$ (Figures 3 and 4).

\section{Discussion}

Previous studies have reported low D1 activities in different malignant tumors, including papillary thyroid cancer [3], lung cancer [9], and renal clear cell cancer [8], as well as in benign tumors such as pituitary adenoma [10, 11]. Decreased D1 activity has also been found in papillary and follicular thyroid cancer cell lines as well as in liver hemangioma compared to healthy parenchyma [5-11]. Additionally, proinflammatory cytokines have been postulated to be one of the factors inhibiting D1 activity [15]. On the other hand, Davies et al., by analyzing D1 enzyme activity in phi1 rat liver cells stimulated by TNF- $\alpha$, IL-1 $\beta$, and IL-6, did not support this hypothesis [23]. The availability of vitamin $D$ may also play a role in D1 activity inhibition. A study carried out by Macejova et al. reported reduction in D1 enzyme activity in the livers of rats treated with vitamin D [24].

On the whole, the D1 activity between HCC and FNH did not show any statistically significant dif-

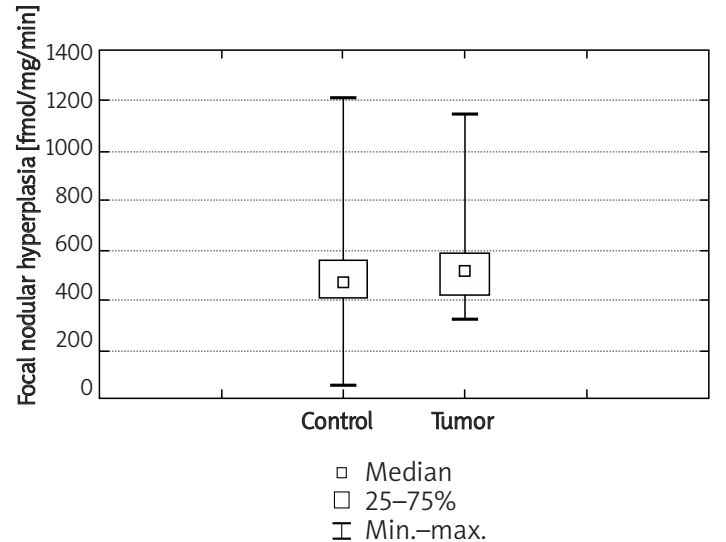

Figure 2. Comparison of D1 activity in FNH and surrounding healthy liver control cells

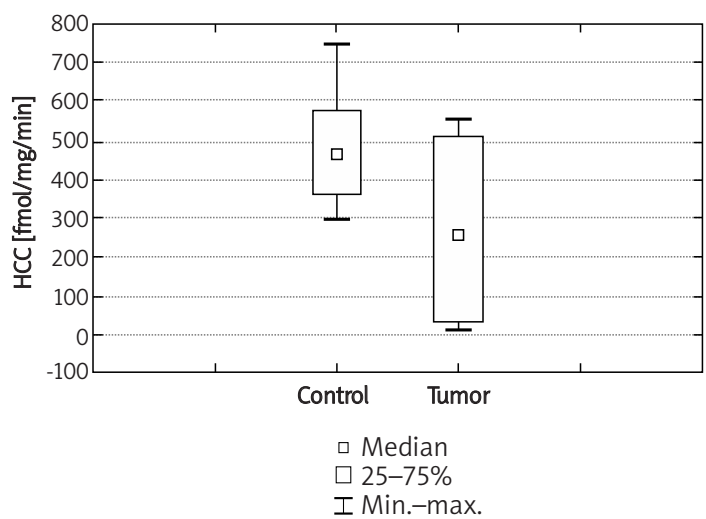

Figure 4. Comparison of D1 activity in HCC and surrounding healthy liver control

ferences as compared to healthy liver parenchyma. However, close observation of individual cases reveals some significant changes. For instance, case 4 of the FNH group shows decreased D1 enzyme activity within the healthy liver (Figure 1). This variation in the data in case 4 may be due to an undiscovered underlying disease. The patient in question suffered from primary sclerosing cholangitis (PSC) and ulcerative colitis, unlike the remaining patients in the FNH group. Studies have demonstrated that PSC initiates thyroid dysfunction with reduced D1 levels in a manner similar to primary biliary cirrhosis [25]. On the other hand, a study carried out in Italy showed that only approximately $3 \%$ of patients with ulcerative colitis also had either hyperthyroidism or hypothyroidism [26]. Therefore, in case 4, rather than the explanation being a significant increase of type D1 deiodinase in $\mathrm{FNH}$, it may alternatively be a relative decrease in normal parenchyma D1 activity which is due to the primary liver disease.

In the HCC group, cases 1 and 7 showed a significant decrease in D1 enzymatic activity within 
the HCC tumor as compared to the control and the remaining HCC cases (Figure 3). We further investigated tumor markers and found elevated levels of $\alpha$-fetoprotein (AFP) above $500 \mu \mathrm{g} / \mathrm{l}$ (normal level: up to $40 \mu \mathrm{g} / \mathrm{l})$ in 3 of the 7 cases of HCC. Of the 3 cases, 2 cases showing elevated AFP levels also exhibited decreased D1 enzyme activity within the HCC tumor. Interestingly, a high level of AFP is an indicator of poor survival [27]. This could support the evidence of low D1 activity observed in other cancers. Low D1 activity within a tumor might be an indicator of high tumor cell grade and poor differentiation. Tumor cells do not resemble native hepatocytes, which results in decreased D1 activity and may influence the aggressiveness of the tumor. Thus one may speculate that D1 activity in these two cases behaves in a manner typical for other carcinomas.

On the other hand, in liver cirrhosis, diminished T3 levels are considered to be an adaptive process to reduce the basal metabolic rates within hepatocytes and to preserve liver to preserve liver function, possibly through reduced D1 reactivity since D1 is responsible for approximately $40 \%$ of the conversion of T4 to T3 in the liver [28]. It might partly explain the higher level of D1 enzyme activity in some HCC cases compared with normal controls.

Potentially, D1 enzymatic activity can be an indicator not only of advanced HCC but also the extent of hepatocyte dysfunction secondary to cirrhosis.

In the cases other than the ones mentioned above for the FNH and HCC groups, D1 enzymatic activity did not deviate far from the controls. There were no significant differences regarding D1 enzyme activity between healthy liver parenchyma and either HCC or FNH. This may be attributable to the same cell origin of both of these tumors, which are mainly derived from liver parenchymal cells. This suggests that this metabolic pathway in the tumor cells is similar to those in healthy tissues; thus D1 activity is not altered in most instances by the neoplastic transformation.

There may be a correlation between hepatocytes and D1 activity, since tumors associated with hepatocytes show little to no change in D1 activity whereas liver hemangiomas, the most frequently encountered benign liver tumors, exhibit significantly altered D1 activity [7]. It is important to bear in mind that liver hemangiomas are not derived from hepatocytes as case of HCC and FNH.

Our findings demonstrate unaltered D1 activity in most of the cases of FNH and HCC examined in this study. The results show that there were very few cases within the FNH and HCC groups with increased D1 enzymatic activity and decreased activity, respectively. This suggests that thyroid hormones play an unknown role in these types of liver tumors. Further investigations may help gain insights into the differentiation of these tumors. Generalization of the results indicates that D1 activity is related to the type of cells from which the tumor is derived. Analyzing individual cases of the two tumor groups revealed that thyroid hormones might have an impact on varying stages of tumorigenesis, and may hold the key for further differentiation and diagnosis of these liver tumors.

In conclusion, D1 enzyme activity was not significantly different between FNH, HCC and healthy liver parenchyma. The obtained results did not make it possible to formulate criteria for tumor differentiation based on D1 activity. However, in selected cases it may provide insights into further differentiation and grading of HCC.

\section{References}

1. Bianco AC, Salvatore D, Gereben B, Berry MJ, Larsen PR. Biochemistry, cellular and molecular biology, and physiological roles of the iodothyronine selenodeiodinases. Endocr Rev 2002; 23: 38-89.

2. Salvatore D, Bartha T, Harney JW, Larsen PR. Molecular biological and biochemical characterization of the human type 2 selenodeiodinase. Endocrinology 1996; 137: 3308-15.

3. Ambroziak M, Pachucki J, Stachlewska-Nasfeter E, Nauman J, Nauman A. Disturbed expression of type 1 and type 2 iodothyronine deiodinase as well as titf1/nkx2-1 and pax-8 transcription factor genes in papillary thyroid cancer. Thyroid 2005; 15: 1137-46.

4. de Souza Meyer EL, Dora JM, Wagner MS, Maia AL. Decreased type 1 iodothyronine deiodinase expression might be an early and discrete event in thyroid cell dedifferentation towards papillary carcinoma. Clin Endocrinol (Oxf) 2005; 62: 672-8.

5. Arnaldi LA, Borra RC, Maciel RM, Cerutti JM. Gene expression profiles reveal that DCN, DIO1, and DIO2 are underexpressed in benign and malignant thyroid tumors. Thyroid 2005; 15: 210-21.

6. Schreck R, Schnieders F, Schmutzler C, Kohrle J. Retinoids stimulate type I iodothyronine 5'-deiodinase activity in human follicular thyroid carcinoma cell lines. J Clin Endocrinol Metab 1994; 79: 791-8.

7. Kornasiewicz O, Debski M, Stepnowska M, Szalas A, BarAndziak E, Krawczyk M. The enzymatic activity of type 1 iodothyronine deiodinase (D1) is low in liver hemangioma: a preliminary study. Arch Immunol Ther Exp (Warsz) 2010; 58: 77-80.

8. Pachucki J, Ambroziak M, Tanski Z, Luczak J, Nauman J, Nauman A. Type I 5'-iodothyronine deiodinase activity and $\mathrm{mRNA}$ are remarkably reduced in renal clear cell carcinoma. J Endocrinol Invest 2001; 24: 253-61.

9. Wawrzynska L, Sakowicz A, Rudzinski P, Langfort R, Kurzyna $M$. The conversion of thyroxine to triiodothyronine in the lung: comparison of activity of type I iodothyronine 5' deiodinase in lung cancer with peripheral lung tissues. Monaldi Arch Chest Dis 2003; 59: 140-5.

10. Baur A, Buchfelder M, Kohrle J. Expression of 5'-deiodinase enzymes in normal pituitaries and in various human pituitary adenomas. Eur J Endocrinol 2002; 147: 263-8.

11. Tannahill LA, Visser TJ, McCabe CJ, et al. Dysregulation of iodothyronine deiodinase enzyme expression and function in human pituitary tumours. Clin Endocrinol (Oxf) 2002; 56: 735-43. 
12. Debski MG, Pachucki J, Ambroziak M, Olszewski W, BarAndziak E. Human breast cancer tissue expresses high level of type 1 5'-deiodinase. Thyroid 2007; 17: 3-10.

13. Garcia-Solis P Aceves C. 5'Deiodinase in two breast cancer cell lines: effect of triiodothyronine, isoproterenol and retinoids. Mol Cell Endocrinol 2003; 201: 25-31.

14. Gonzalez-Sancho JM, Garcia V, Bonilla F, Munoz A. Thyroid hormone receptors/THR genes in human cancer. Cancer Lett 2003; 192: 121-32.

15. Jakobs TC, Mentrup B, Schmutzler C, Dreher I, Kohrle J. Proinflammatory cytokines inhibit the expression and function of human type I 5'-deiodinase in HepG2 hepatocarcinoma cells. Eur J Endocrinol 2002; 146: 559-66.

16. Ho J, Kendrick V, Dewey D, Pacaud D. New insight into the pathophysiology of severe hypothyroidism in an infant with multiple hepatic hemangiomas. J Pediatr Endocrinol Metab 2005; 18: 511-4.

17. Huang SA, Mulcahey MA, Crescenzi A, et al. Transforming growth factor-beta promotes inactivation of extracellular thyroid hormones via transcriptional stimulation of type 3 iodothyronine deiodinase. Mol Endocrinol 2005; 19: 3126-36.

18. Konrad D, Ellis G, Perlman K. Spontaneous regression of severe acquired infantile hypothyroidism associated with multiple liver hemangiomas. Pediatrics 2003; 112: 1424-6.

19. Bosch FX, Ribes J, Diaz M, Cleries R. Primary liver cancer: worldwide incidence and trends. Gastroenterology 2004; 127: S5-16.

20. Yang Y, Fu S, Li A, et al. Management and surgical treatment for focal nodular hyperplasia in children. Pediatr Surg Int 2008; 24: 699-703.

21. Cherqui D, Rahmouni A, Charlotte F, et al. Management of focal nodular hyperplasia and hepatocellular adenoma in young women: a series of 41 patients with clini$\mathrm{cal}$, radiological, and pathological correlations. Hepatology 1995; 22: 1674-81.

22. Visser TJ, Kaplan MM, Leonard JL, Larsen PR. Evidence for two pathways of iodothyronine 5'-deiodination in rat pituitary that differ in kinetics, propylthiouracil sensitivity, and response to hypothyroidism. J Clin Invest 1983; 71: 992-1002.

23. Davies PH, Sheppard MC, Franklyn JA. Inflammatory cytokines and type $15^{\prime}$-deiodinase expression in phi1 rat liver cells. Mol Cell Endocrinol 1997; 129: 191-8.

24. Macejova D, Ondkova S, Brtko J. Vitamin D3 affects expression of thyroid hormone receptor alpha and deiodinase activity in liver of MNU-treated Sprague-Dawley rats. Gen Physiol Biophys 2009; 28: 363-70.

25. Silveira MG, Mendes FD, Diehl NN, Enders FT, Lindor KD. Thyroid dysfunction in primary biliary cirrhosis, primary sclerosing cholangitis and non-alcoholic fatty liver disease. Liver Int 2009; 29: 1094-100.

26. Casella G, De Marco E, Antonelli E, et al. The prevalence of hyper- and hypothyroidism in patients with ulcerative colitis. J Crohns Colitis 2008; 2: 327-30.

27. Johnson PJ, Melia WM, Palmer MK, Portmann B, Williams R. Relationship between serum alpha-foetoprotein, cirrhosis and survival in hepatocellular carcinoma. $\mathrm{Br}$ J Cancer 1981; 44: 502-5.

28. Malik R Hodgson $\mathrm{H}$. The relationship between the thyroid gland and the liver. QJM 2002; 95: 559-69. 